\title{
Probability-Based Design and Life Cycle Assessment of a Spun Concrete Pole
}

\author{
Petr Štěpánek, Ivana Laníková*, Petr Šimůnek \\ Institute of Concrete and Masonry Structures \\ Brno University of Technology \\ Brno, Czech Republic \\ stepanek.p@fce.vutbr.cz, lanikova.i@fce.vutbr.cz, simunek.p@fce.vutbr.cz
}

\begin{abstract}
This contribution compares concrete structure design results obtained via the partial reliability factor method and using a probability-based method. The Monte Carlo simulation method, modified by the Latin Hypercube Sampling method, was used to calculate the reliability of a designed structure. Economic and ecological aspects (acquisition costs, $\mathrm{CO}_{2}$ and $\mathrm{SO}_{2}$ emissions and embodied energy associated with the concrete member through the production, utilization and demolition stages of its life cycle) were taken into account when assessing the quality of the design. An example of a designed structure - a prestressed spun concrete pole manufactured from reinforced concrete - is presented.
\end{abstract}

Keywords - concrete structure; reinforced concrete; probability based design; environmental aspects

\section{INTRODUCTION}

Most standards enable the use of a variety of methods to design a particular structure. The outcome of these methods depends on the level of simplification of the calculation within a particular procedure, the quality of the input data, the expertise of the engineer, and the amount of time he has available to spend on the structural design.

The design process includes a lot of uncertainties, especially

- The randomness of physical quantities used in the design (as a natural characteristic of each quantity),

- Statistical uncertainties caused by a lack of data during the description of a particular quantity,

- Model uncertainties caused by inaccuracies in the calculation model in comparison with real structural behavior,

- Uncertainties caused by inaccuracies in the limit state definition,

- Mistakes and human element deficiencies within the design procedure (as well as those occurring during the execution, maintenance and usage of the structure), along with incomplete understanding of real material and structural behavior.

This outcome has been achieved with the financial support of the Ministry of Trade and Industry of the Czech Republic within the research project FR-TI4/159 "Light structures - progressive structures from modern composite materials" and under project No. TA03030851 "Rehabilitation of tunnels - technology, materials and methodology" supported by the Technology Agency of the Czech Republic.
In the classic approach to evaluating the reliability of a structure using the partial reliability factor method (PFM), the first three above-mentioned groups of uncertainties are hidden within the partial reliability factors, which are determined separately both for the effects of load $E$ and for structural resistance $R$. During the application of this approach it is not necessary to know the particular "values" of the uncertainties. The reliability review is simplified within the observance of rules and recommendations, but the real probabilistic basis of the reliability stays hidden. The partial reliability factor method is currently mostly used for the design of a structure from the standpoint of ultimate states. This method is used especially for its simplicity and the ease of obtaining input data. The input data relating to the structure's function and its location are gained from the used materials and loads. Characteristic input data values are given in relevant parts of the standards and drawing documentation.

However, standard [1] also enables the application of probability-based method (PBM) in the design of structures. Basic information regarding this option is mentioned in [1] and [2]. The probabilistic formulation procedure expressing structural reliability considers the variable quantities entering the calculation to be random quantities whose uncertainties can be described by means of mathematical statistical methods. This approach requires either information regarding the probability distribution of these quantities, or at least data on the distribution of the statistical parameters, and possibly on the mutual statistical dependence or independence of individual quantities.

The reliability of a structure is usually expressed with the help of the failure function $Z=g(R, E)$. From the calculated distribution of the failure function it is possible to formulate a reliability condition using the structural failure probability $p_{\mathrm{f}}$, or alternatively using the reliability index $\beta$, see [3].

Analytical representation of the failure function is only possible in simple cases, and thus its application is limited. The failure function $Z$ generally depends on the number of random quantities, but their distributions do not always correspond to the normal distribution. The relations for determining the effect of loading $E$ and resistance function $R$ are often complicated and non-linear. As a result, numerical methods (simulation, semi analytical) are used for failure probability calculation. 


\section{EXAMPLE StRUCtURE - A SPUn CONCRETE POlE}

The reinforcement of the pole is fabricated from prestressed indented $6 \mathrm{~mm}$ diameter Y1570C wires (øPN6) which are supplemented by $10 \mathrm{~mm}$ diameter B500B passive reinforcement (øR10). The prestressing wires are situated along the entire pole and are bond-anchored both at the top and at the bottom of the pole. Various lengths of passive (non prestressed) reinforcement are used in order to enhance the bearing capacity of the pole. The pole has an annular crosssection. The geometry of the pole is shown in Fig. 1.

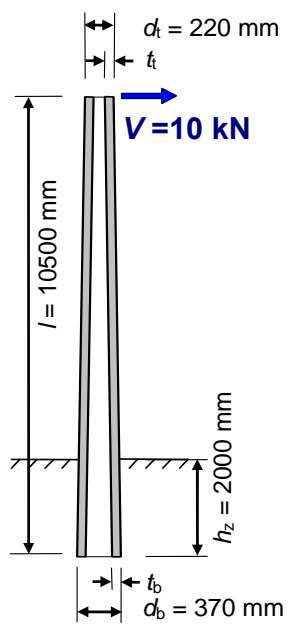

Fig. 1. Pole geometry

The pole is loaded by the top horizontal force $\mathrm{V}$. The characteristic value is $\mathrm{V}=10 \mathrm{kN}$. It includes the tensions of cable lines and also climatic effects (such as wind and icing on overhead lines).

The resulting design has to meet the following reliability conditions:

- Ultimate limit state (ULS): the pole is loaded by a normal force load (caused by prestressing) and bending moment (caused by the top horizontal force, $\mathrm{V}$ ) in predefined discrete cross-sections along the pole length;

- $\quad$ Serviceability limit state (SLS): the width of the crack for $1.0 \mathrm{~V}$ load, the crack origin at $0.5 \mathrm{~V}$ load and deformation control should all be checked.

The design was based on the assumption that the geometry of the pole is unchangeable (it is determined by the mold in which it is produced); only the thickness of the concrete, the number of prestressed strands and the passive reinforcement (the number and length of bars) were allowed to be changed. The maximum amount of prestressing wires was fixed due to the limitation imposed by the minimum permitted distance between wires at the head of the pole ( 20 pcs); only an even number of wires is possible. The minimum thickness of the cross-section at the pole head $\left(t_{\mathrm{t}}\right)$ was $60 \mathrm{~mm}$; it was $70 \mathrm{~mm}$ at the foot of the pole $\left(t_{\mathrm{b}}\right)$.

\section{A. Input Variables and Characteristics}

The statistical distributions of material characteristics and some geometric characteristics were provided by the producer of the poles in the Czech Republic (Sloupárna Majdaléna). The uncertainties of the resistance model $R$ and the calculation of the effect of loading $E$ were taken from the recommendations of the JCSS Probabilistic model code [4]. This specifically deals with the following random quantities:

- The material characteristics of concrete (compressive and tensile strength, modulus of elasticity, ultimate strain of compressed concrete), non-prestressing bars (yield strength, ultimate strength, ultimate tensile strain, reinforcement area), prestressing wires (ultimate strength, modulus of elasticity, ultimate tensile strain);

- Geometrical characteristics, such as foundation depth (fixation), concrete cover of reinforcement;

- Horizontal loading by the top force $V$ (see Fig. 1).

The other quantities were considered to be deterministic.

In accordance with the recommendation of the JCSS [4], the uncertainties of the resistance model $R$ and the calculation of the effect of loading $E$ should also be included in the reliability calculation by means of random variables $\theta_{\mathrm{R}}$ and $\theta_{\mathrm{E}}$.

Design and assessment were carried out with software based on the algorithms determined and mentioned in [5]. This software was set up primarily for use with the partial factor method but then was modified for application in fully probabilistic design. The Monte Carlo simulation method was used for reliability calculations, modified by the Latin Hypercube Sampling method (LHS). For each calculation (500 numerical simulations were performed), a vector of the random quantities was individually generated using FREET computer software. This program provides (with the help of the Simulated Annealing method) the required statistical dependence or independence for the generated random quantities according to a predetermined correlation matrix. The virtual numerical simulations for examined cross-sections provided function value files for the effect of loading $E$, structural resistance $R$ and failure function $Z$ for the ULS analysis. Others values, such as the top deflection, the development of cracks and their propagation along the pole length were used in reviewing the structure in terms of the SLS. These quantity distribution parameters were estimated with the help of statistical methods and the failure probability was determined together with the reliability index.

\section{B. Pole Design}

A comparison of both the above-mentioned design methods, the PFM and a described PBM, was performed. The design was primarily carried out by the PFM (for a pole with the maximum amount of prestressing wires (20 wires (øPN6)) and the minimum cross-section thickness at the pole head $\left(t_{\mathrm{t}}=\right.$ $60 \mathrm{~mm})$ and the pole foot $\left(t_{\mathrm{b}}=70 \mathrm{~mm}\right)$ only). The amount of passive reinforcement in the critical cross-section is 17 bars (øR10) $(20 ø \mathrm{PN} / 17 \varnothing \mathrm{R}$ in the table below). The pole fulfills the 
reliability condition and the resulting design and reliability are summarized in Table I.

\section{1) Ultimate limit state}

The PFM designed pole was checked by the PBM. The reliability index (ULS) for the normal distribution of failure function $Z$ with the parameters $\mathrm{N}(162.0 ; 39.43)$ is $\beta=4.11$, and the failure probability is $p_{\mathrm{f}}=1.99 \cdot 10^{-5}$. According to Eurocode [1], the pole can be classed as reliability class RC2, for which a minimum reliability index of $\beta_{0}=3.8$ is recommended for the ULS as well as for a reference time of 50 years. It is thus evident that this structure can be designed more economically when using the probability-based method.

Fig. 2 displays records showing the dependence of the reliability index on the initial prestressing (maximal allowable stress $\sigma_{\mathrm{p}, \max }=1188 \mathrm{MPa}$ ) for the different calculations conducted for both the active and passive reinforcement. It is evident from the graph that for predefined statistical parameters of designed quantities, the assessed cross-section of the pole will satisfy the ULS criteria even with a lower amount of reinforcement. All of the reinforcement designs presented in the graph whose curves are above the reliability index value $\beta_{0}=3.8$ (marked by a dashed line) will satisfy the criteria. A reduction in tension does not reduce the reliability index, but rather increases it.

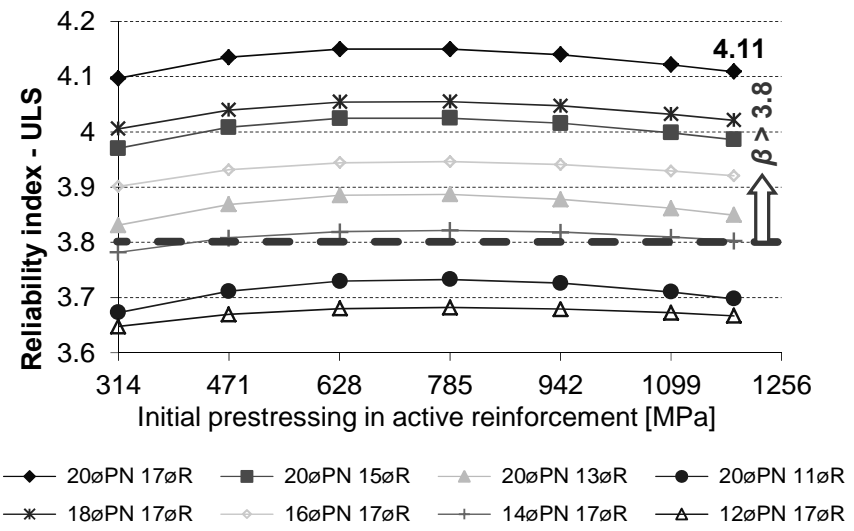

Fig. 2. Reliability index ULS

\section{2) Serviceability limit state}

Only poles whose critical cross-sections met the requirements of the ULS reliability index were evaluated from the SLS perspective. The designed passive reinforcement length needed to be such that SLS assessments could be carried out throughout the length of the pole. The length of the reinforcement bars was designed so that the ULS reliability condition (i.e. the reliability index) was not exceeded in any cross-section of the pole.

During the assessment of the deflection limit of the pole, the failure function was defined as the difference between the relevant serviceability criterion (deflection limit $f_{0}$ ) and the deflection of load $f$. The deflection limit is defined as $4 \%$ of the length of the pole above the ground, i.e. $0.340 \mathrm{~m}$. The obtained set of results is approximated by the normal distribution with a mean value of $0.076 \mathrm{~mm}$ and a standard deviation of $0.059 \mathrm{~mm}$. The corresponding reliability index is $\beta=4.45$, which fulfils the reliability condition for a reversible serviceability limit state (reliability class RC2 and a reference time of 50 years) that is expressed by the value $\beta_{0}=0\left(p_{0}=\right.$ 0.5 ). According to the PBM, all designed poles comply with this criterion.

During the monitoring of crack initiation and crack widths throughout the pole length, the assessed quantity (crack initiation or crack widths) is random variable with Bernoulli distribution, and therefore failure probability was evaluated instead of the reliability index. Both of these failures are irreversible serviceability limit states for which a reliability value of $\beta_{0}=1.5$ is prescribed with a corresponding probability of failure of $p_{0}=0.0668$. The highest probability of failure occurred at the point of fixation of the pole, i.e. at the point of the maximal moment. The graph in Fig. 3 shows that all prestressed poles with the full amount of active reinforcement $20 \varnothing \mathrm{PN} 6$ (initial stress in the active reinforcement $\sigma_{\mathrm{p}, \max }=1188 \mathrm{MPa}$ ) and the pole with $18 ø$ PN6 and $17 ø \mathrm{R} 10\left(\sigma_{\mathrm{p}, \max }=1188 \mathrm{MPa}\right)$ will satisfy the crack development criteria.

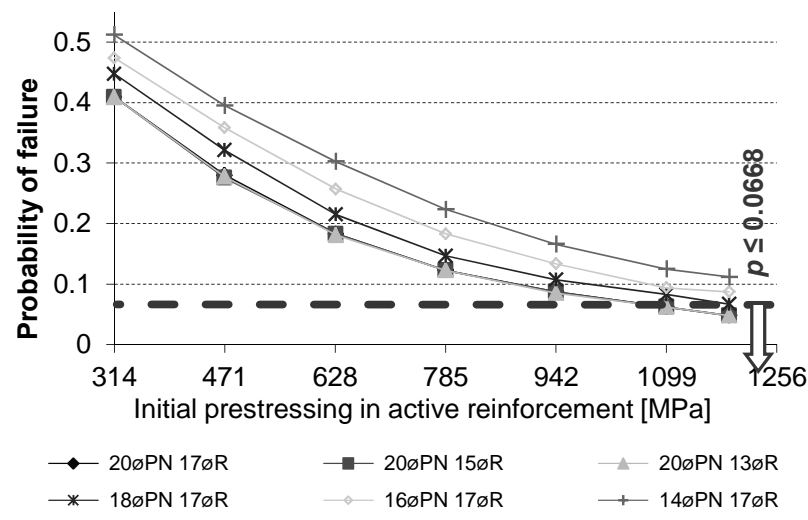

Fig. 3. Probability of crack development at $0.5 \mathrm{~V}$

During the assessment of crack widths using the PBM, i.e. during individual simulations of a particular cross-section, the following could occur

- A crack did not occur - failure-free state,

- A crack occurred, but its width did not exceed the limit width $w_{0}$ - failure-free state,

- A crack occurred and its width exceeded the limit.

From the resulting graphs (Fig. 4) it is evident that all of the poles satisfy the reliability criterion.

The most suitable designs, which successfully fulfilled the reliability condition (for the maximal initial allowable stress $\sigma_{\mathrm{p}, \max }=1188 \mathrm{MPa}$ ), are the pole with the full amount of active reinforcement $20 ø \mathrm{PN} 6$ and the minimum amount of reinforcement $13 ø \mathrm{R} 10$ (pole type PT1 in the table below), and the pole with $18 ø$ PN6 and $17 ø$ R10 (pole type PT2 below). Both of them have a minimum cross-section thickness of $60 \mathrm{~mm}$ at the pole head and $70 \mathrm{~mm}$ at the foot of the pole. For the next assessment a pole was designed with a thicker 
TABLE I. SUMMARY OF DESIGNED POLES AND THE GEOMETRY, RELIABILITY, VOLUME AND WEIGHT OF THE USED MATERIAL

\begin{tabular}{|c|c|c|c|c|c|}
\hline \multirow{2}{*}{\multicolumn{2}{|c|}{ Pole type }} & \multicolumn{3}{|c|}{ Pole designed by PBM } & \multirow[t]{2}{*}{ Pole designed by PFM } \\
\hline & & PT1 & PT2 & PT3 & \\
\hline \multicolumn{6}{|l|}{ Geometry and reinforcement } \\
\hline \multicolumn{2}{|l|}{ Thickness of cross-section $t_{\mathrm{t}} / t_{\mathrm{b}}$} & $\begin{array}{c}60 \mathrm{~mm} / 70 \\
\mathrm{~mm}\end{array}$ & $\begin{array}{c}60 \mathrm{~mm} / 70 \\
\mathrm{~mm}\end{array}$ & $\begin{array}{c}70 \mathrm{~mm} / 80 \\
\mathrm{~mm}\end{array}$ & $60 \mathrm{~mm} / 70 \mathrm{~mm}$ \\
\hline \multicolumn{2}{|l|}{$\begin{array}{l}\text { Reinforcement: of the critical cross-section } \\
\text { i.e. pcs / length: }\end{array}$} & $\begin{array}{l}13 ø \mathrm{R} \\
7 ø \mathrm{R} / 6.13 \mathrm{~m} \\
6 ø \mathrm{R} / 3.86 \mathrm{~m}\end{array}$ & $\begin{array}{l}17 ø \mathrm{R} \\
9 ø \mathrm{R} / 6.79 \mathrm{~m} \\
8 ø \mathrm{R} / 4.32 \mathrm{~m}\end{array}$ & $\begin{array}{l}12 ø \mathrm{R} \\
6 ø \mathrm{R} / 5.92 \mathrm{~m} \\
6 ø \mathrm{R} / 3.92 \mathrm{~m}\end{array}$ & $\begin{array}{l}17 ø \mathrm{R} \\
9 ø \mathrm{R} / 6.79 \mathrm{~m} \\
8 ø \mathrm{R} / 4.32 \mathrm{~m}\end{array}$ \\
\hline \multicolumn{2}{|l|}{ Prestressing wires } & $20 ø \mathrm{PN}$ & $18 ø \mathrm{PN}$ & $20 ø \mathrm{PN}$ & $20 ø \mathrm{PN}$ \\
\hline Reliability evaluated by PFM & Limit value & & & & \\
\hline Reliability index of ULS & 3.80 & $3.85^{\text {a) }}$ & 4.02 & $3.8^{\mathrm{a})}$ & 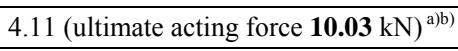 \\
\hline Reliability index of deflection & 1.50 & 4.02 & 4.04 & 3.96 & 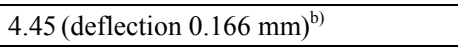 \\
\hline $\begin{array}{l}\text { Probability of exceeding the limit crack width } \\
\text { for } 1.0 \mathrm{~V}\end{array}$ & 0.0668 & 0.0261 & 0.0235 & 0.0386 & 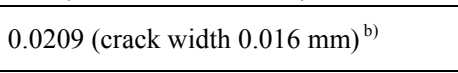 \\
\hline Probability of crack origin at $0.5 \mathrm{~V}$ & 0.0668 & 0.0482 & $0.0668^{a)}$ & 0.0482 & $0.0482(\text { cracks are not expected })^{b)}$ \\
\hline \multicolumn{6}{|l|}{ Volume and weight of materials } \\
\hline \multicolumn{2}{|l|}{ Concrete volume } & $0.497 \mathrm{~m}^{3}$ & $0.497 \mathrm{~m}^{3}$ & $0.548 \mathrm{~m}^{3}$ & $0.497 \mathrm{~m}^{3}$ \\
\hline \multicolumn{2}{|l|}{ Weight of reinforcement } & $40.73 \mathrm{~kg}$ & $60.43 \mathrm{~kg}$ & $36.40 \mathrm{~kg}$ & $58.98 \mathrm{~kg}$ \\
\hline \multicolumn{2}{|l|}{ Weight of prestressing wires } & $46.61 \mathrm{~kg}$ & $41.95 \mathrm{~kg}$ & $46.61 \mathrm{~kg}$ & $46.61 \mathrm{~kg}$ \\
\hline
\end{tabular}

cross-section, i.e. $70 \mathrm{~mm}$ at the pole head and $80 \mathrm{~mm}$ at the foot of the pole; the reinforcement is made from $20 \varnothing$ PN6 and cross-section, i.e. $70 \mathrm{~mm}$ at the pole head and $80 \mathrm{~mm}$ at the foot of the pole; the reinforcement is made from $20 \varnothing$ PN6 and $12 ø \mathrm{R} 10$ (pole type PT3 below) too. The resulting designs, the amounts of materials and the reliability of the poles are summarized in Table 1.

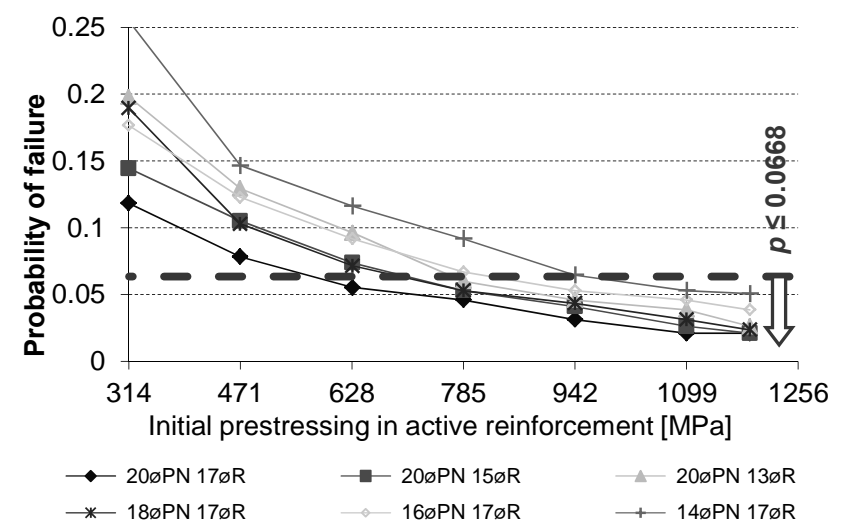

Fig. 4. Probability of exceeding the limit crack width for $1.0 \mathrm{~V}$

\section{Quality Design Criterion}

Factors that can be taken into account when assessing the suitability of a design include those of an economic nature as well as those concerning the following ecological aspects: consumption of primary raw materials, water consumption, global warming potential (GWP), acidification potential (AP), photochemical ozone creation potential (POCP), primary energy consumption, the amount of recyclable (reusable) materials and/or members (at the end of the lifetime of the analyzed structure), and the amount of unrecyclable/unreusable materials/members (amount of waste). It is possible to express:

- The GWP via equivalent global warming potential

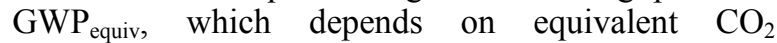
emissions (calculated for greenhouse gases $\mathrm{CO}_{2}, \mathrm{CO}$, $\mathrm{NO}_{x}, \mathrm{CH}_{6}$ and $\mathrm{N}_{2} \mathrm{O}$ );

- The AP as equivalent acidification potential, $\mathrm{AP}_{\text {equiv }}$, which depends on equivalent $\mathrm{SO}_{2}$ emissions (calculated for chemical substances $\mathrm{SO}_{2}, \mathrm{NO}_{\mathrm{x}}, \mathrm{NH}_{3}$, $\mathrm{HCl}$ and $\mathrm{H}_{2} \mathrm{~S}$ );

- The POCP as equivalent photochemical ozone creation potential, $\mathrm{POCP}_{\text {equiv }}$, which is dependent on the equivalent emission of ethylene $\left(\mathrm{C}_{2} \mathrm{H}_{4, \text { eqv }}\right)$ obtained from chemical substances $\mathrm{C}_{2} \mathrm{H}_{4}, \mathrm{C}_{2} \mathrm{H}_{6}, \mathrm{CH}_{4}, \mathrm{C}_{7} \mathrm{H}_{8}$, acetate, and aldehyde.

In this study we have considered the aspects mentioned above for two cases:

- Only for the construction process phase: transport and consumption of raw and other materials, concrete mixture production and the production of concrete members (Fig. 5);

- For all life cycle phases (Fig. 5): transport to the destination (about $300 \mathrm{~km}$ ); maintenance and repair work is not common or necessary for this type of structure and the dismantling or demolition of the structure is assumed (with a transportation distance of about $100 \mathrm{~km}$ ).

The environmental aspects of the construction process phase, some types of transport and the unit costs and environmental impacts of the end of the structure's life cycle are referred to in [6] and [7]. 


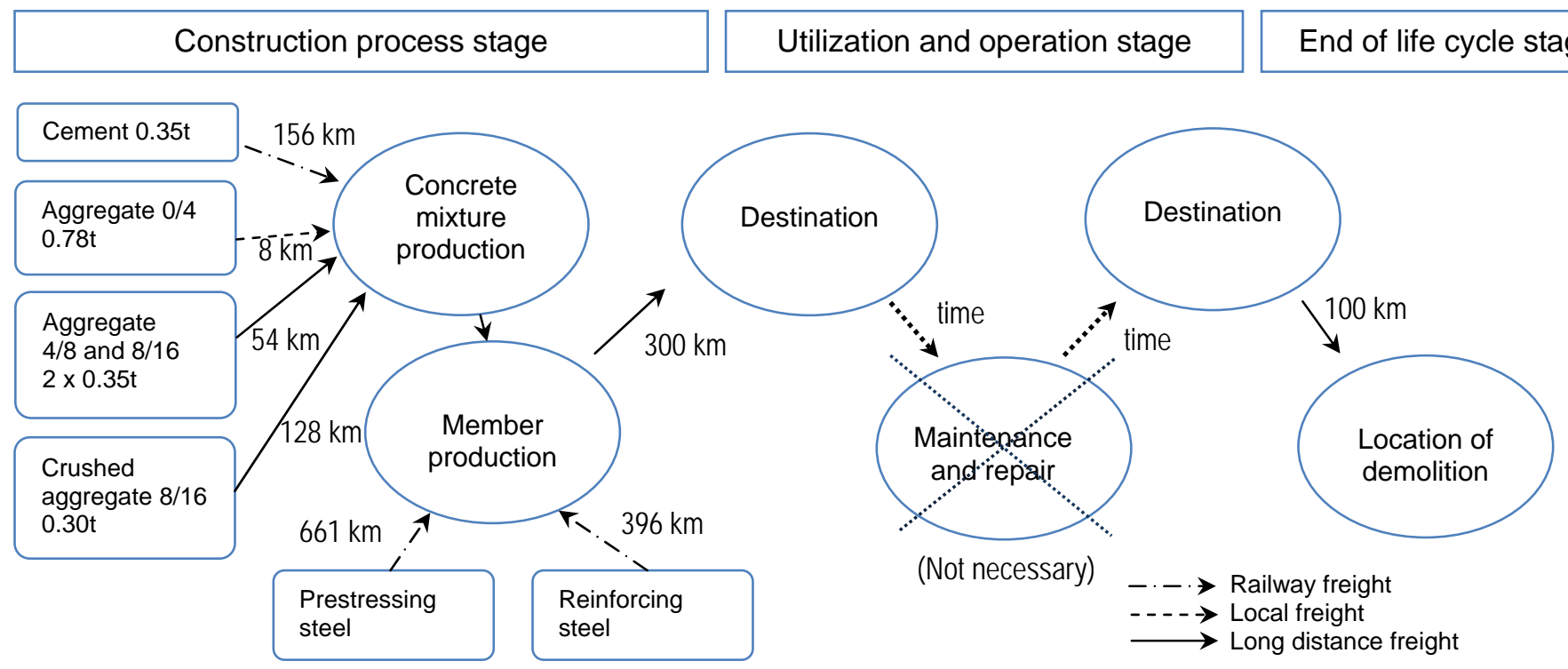

Fig. 5. Life cycle - individual concrete components, distances, and types of transportation

The assessment of the quality of a design with regard to the above-mentioned aspects can be performed in advance with the help of a criterion set - a design quality criterion (e.g. an objective function). This design quality criterion describes the cost of the execution of the pole, the environmental impact (expressed in terms of primary energy consumption), the equivalent global warming potential, the equivalent acidification potential and the equivalent photochemical ozone creation potential.

The following aspects were not included in the design quality criterion: consumption of primary raw materials, water consumption, the amount of recyclable (reusable) materials and the amount of unrecyclable/unreusable materials/members (the amount of waste). The function (design quality criterion), can be expressed in the form

$$
\begin{gathered}
f(x)=+\alpha_{\mathrm{GWP}} \frac{G W P_{\mathrm{tot}, \text { equiv }}(\{x\})}{{ }^{0} G W P_{\text {tot } \text { equiv }}}+ \\
+\alpha_{\mathrm{AP}} \frac{A P_{\text {tot, equiv }}(\{x\})}{{ }^{0} A P_{\text {tot, equiv }}}+\alpha_{\mathrm{POCP}} \frac{P O C P_{\text {tot, equiv }}(\{x\})}{{ }^{0} P O C P_{\text {tot, equiv }}}+ \\
+\alpha_{\mathrm{E}} \frac{E_{\text {tot }}(\{x\})}{{ }^{0} E_{\text {tot }}}+\alpha_{\mathrm{C}} \frac{C_{\text {tot }}(\{x\})}{{ }^{0} C_{\text {tot }}}
\end{gathered}
$$

where, the used symbols have the following meanings: $C_{\text {tot }}(\{x\})$ is the total acquisition costs; $G W P_{\text {tot,equiv }}(\{x\})$ is the total equivalent global warming potential; $A P_{\text {totequiv }}(\{x\})$ is the total acidification potential; $P O C P_{\text {totequiv }}(\{x\})$ is the total photochemical ozone creation potential; $E_{\text {tot }}(\{x\})$ is the total energy consumption and $\alpha_{\mathrm{C}}$ (or $\alpha_{\mathrm{GWP}}, \alpha_{\mathrm{AP}}, \alpha_{\mathrm{POCP}}$, or $\alpha_{\mathrm{E}}$ ) are weights in the objective function. ${ }^{0} C_{\text {tot }},{ }^{0} G W P_{\text {totequiv }},{ }^{0} A P_{\text {totequiv, }}$, ${ }^{0} P O C P_{\text {tot,equiv }},{ }^{0} E_{\text {tot }}$, are reference values for corresponding quantities calculated for the reference pole defined by the designer.
However, the terms of the design quality criterion have different units and thus cannot be directly summed; for that reason they firstly have to be normalized by the chosen reference values.

\section{Assesment of the Designs}

The assessment of the "quality" of reinforcement design was performed for the design quality criterion function (1), for which two alternative weighting coefficients were considered. In the case of the first alternative (alt.1), only the total acquisition costs for the whole life cycle were a decisive criterion (the weighting coefficients were set as follows: $\alpha_{\mathrm{GWP}}$ $\left.=\alpha_{\mathrm{AP}}=\alpha_{\mathrm{POCP}}=\alpha_{\mathrm{E}}=0 ; \alpha_{\mathrm{C}}=1.0\right)$, while with the second alternative (alt. 2), only environmental aspects for the whole life cycle were taken into account $\left(\alpha_{\mathrm{GWP}}=\alpha_{\mathrm{AP}}=\alpha_{\mathrm{POCP}}=\alpha_{\mathrm{E}}=\right.$ $\left.0.25 ; \alpha_{\mathrm{C}}=0\right)$.

When evaluating the quality of the designs via the design quality criterion (1), the pole designed via the PFM (see Table 1 ) is considered as a reference value for alternatives 1 and 2; each of those alternatives is compared separately.

The minimum value for this criterion function was achieved by pole type PT1 for both the weight coefficient alternatives (Figs. 6 and 7). In comparison to the pole designed via PFM, the pole PT1 is roughly about $11 \%$ cheaper and about $12 \%$ more environmentally friendly. The result is the same whether one considers the whole life cycle or merely takes just the cost or the environmental impact of the construction process phase into account.

According to Figs. 6 and 7, the best design (pole PT1) was the pole with the minimum cross-section thickness and the maximal amount of prestressing wires. The USL reliability condition (bending moment and normal force) was the limiting criterion. Reducing the amount of prestressing wires meant a considerable increase in the amount of reinforcement 
required due to compliance with the reliability condition of avoiding crack initiation (see pole type PT2 in Fig. 3).

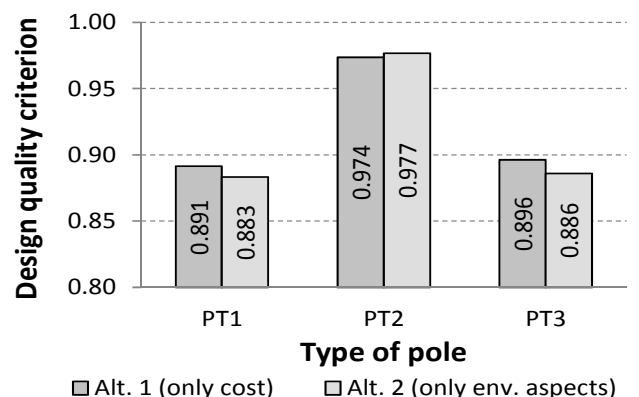

Fig. 6. Evaluation of the design quality criterion for the construction process phase

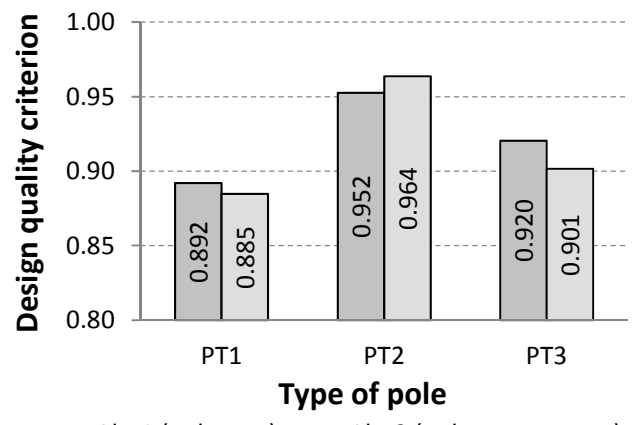

Fig. 7. Evaluation of the design quality criterion for all life cycle phases

If only the construction process phrase is evaluated, the design quality criterion function value for pole PT3 (Fig. 6) is very close to the value obtained for pole PT1 (pole PT3 is only about $0.5 \%$ more expensive and about $0.1 \%$ less environmentally friendly), but the greater weight of pole PT3 caused by its higher concrete volume increased the design quality criterion function value when all phases of the life cycle were assessed (the difference in cost increases by $3 \%$ and environmental friendliness by $2 \%$ ).

\section{CONCLUSIONS}

From the presented study it is evident that both of the methods covered in this paper, the PFM and PBM provide different levels of design reliability. The ULS evaluation obtained results with the greatest difference between them. However, fully probabilistic design requires, in contrast to the partial reliability factor (PFM) method:

- Knowledge of the distribution of input quantities, and of their characteristics;

- A tool for use in redesign calculations combined with statistical evaluation;

- Sufficient professional knowledge.

Probability-based design better reflects the true characteristics of materials and geometry than the partial factor method. The mass production of members (poles) allows long-term monitoring and assessment of the fabricated product. The result is that the quality of products (product characteristics) can be taken into account during the design process.

Materially-optimized structures seem to be environmentally-friendly without there being any explicitly prescribed goal of taking ecological aspects into account. This is because material savings mean less pollution. It is, therefore, preferable to choose a higher amount of reinforcement to reduce the volume of concrete when designing structures.

\section{REFERENCES}

[1] EN 1990: 2002 Eurocode - Basis of structural design.

[2] ISO 2394:1998 (E) General principles on reliability for structures.

[3] P. Štěpánek, I. Laníková, and P. Šimůnek, “Optimization of concrete structures design with environmental aspects inclusion," In ICCS 2013 First International Conference on Concrete Sustainability, Tokyo, Japan, pp. 643-650, 2013.

[4] JCSS: Probabilistic model code, http://www.jcss. ethz.ch

[5] I. Laníková, P. Štěpánek, and P. Šimůnek, "Fully probabilistic design of concrete structures”, In Mendel 2010, BUT Brno, pp. 426 - 433, June 2010.

[6] I. Laníková, P. Šimůnek, and P. Štěpánek, "Optimized design of concrete structures with regard to environmental aspects. In CESB 2013 - Central Europe Towards Sustainable Building, Grada Publication, Prague, pp. 473-476, 2013.

[7] P. Hájek, M. Kynčlová, and C. Fiala, "Life cycle assessment of concrete structures - a step toward environmental savings", Struct. Conc. vol. 12, no. 1 , pp. 13-22, 2011. 